\title{
A new tension induction paradigm unravels tissue response and the importance of E-cadherin in the developing epidermis
}

\author{
NATASHA STEFFI LEWIS 1, ,\#, , GEETIKA CHOUHAN ${ }^{1, \neq}$, VIVEK BELAPURKAR $^{3, \# \#, ~ P R A T E E K ~ A R O R A ~}{ }^{1}$, \\ SATYANARAYAN ${ }^{2}$, SRI RAMA KOTI AINAVARAPU ${ }^{2}$ and MAHENDRA SONAWANE*,1 \\ ${ }^{1}$ Department of Biological Sciences, ${ }^{2}$ Department of Chemical Sciences, Tata Institute of Fundamental Research, \\ Colaba, Mumbai and ${ }^{3}$ Institute of Bioinformatics and Biotechnology, Savitribai Phule Pune University, Pune, India
}

\begin{abstract}
The epidermis, being the outermost epithelial layer in metazoans, experiences multiple external and self-generated mechanical stimuli. The tissue-scale response to these mechanical stresses has been actively studied in the adult stratified epidermis. However, the response of the developing bi-layered epidermis to differential tension and its molecular regulation has remained poorly characterised. Here we report an oil injection based method, which in combination with atomic force microscopy (AFM), allows manipulation as well as estimation of tension in the developing epidermis. Our results show that the injection of mineral oil into the brain ventricle of developing zebrafish embryos stretches the overlying epidermis. The epidermal tension increases linearly with the injected volume of oil and the injection of 14-17 $\mathrm{nL}$ oil results in a two-fold increase in epidermal tension. This increase in epidermal tension is sufficient to elicit a physiological response characterised by temporal changes in the cell cross-sectional area and an increase in cell proliferation. Our data further indicate that the depletion of E-cadherin in the epidermis is detrimental for tissue integrity under increased mechanical stress. The application of this experimental paradigm in a genetically tractable organism such as zebrafish can be useful in uncovering mechanisms of tension sustenance in the developing epidermis.
\end{abstract}

KEY WORDS: ventricular oil injection, AFM, tissue tension, E-cadherin, epidermis, zebrafish

\section{Introduction}

Epidermis is the outer epithelial component of the vertebrate skin. It allows the skin to function as a barrier by preventing the entry of pathogens and by restricting water loss to the surroundings. The early developing epidermis is a bilayered epithelium having an outer peridermal layer and underlying basal epidermis, which eventually develops into a stratified epithelium (reviewed in Koster and Roop, 2007). Being the outermost tissue, the epidermis has to cope with the tension generated due to the underlying dermal fibres (Langer, 1861) and the growth of inner organs. In addition to this pre-stress, the epidermis also experiences tensile, compressive and frictional forces as the organism interacts with its environment (Silver et al., 2003). The epidermal tolerance towards these stresses is thought to be reinforced by cell-cell and cell-matrix adhesion, keratin cytoskeleton, and the underlying extracellular matrix (ECM) (Georges-Labouesse et al., 1996; Lyu et al., 2016; Raghavan et al., 2000; Ray et al., 2013; Reis et al., 1994; Varki et al., 2007). Inability to respond to such forces due to perturbed function of the keratin cytoskeleton, adhesion complexes or ECM can manifest as increased epidermal fragility resulting into blistering diseases like epidermolysis bullosa, palmoplantar keratoderma, etc (Blume-

\footnotetext{
Abbreviations used in this paper: AFM, atomic force microscope; APTMS, 3-aminopropyltrimethoxysilane; BrdU, bromo-5 `-deoxyuridine; cdh1, e-cadherin/cadherin1; cldB, claudin B; ECM, extracellular matrix; FRET, fluorescence resonant energy transfer; hpf, hours post fertilization; hpi, hours post injection; kPa, kiloPascal; LMA, low melting agarose; PAA, polyacrylamide; PBS, phosphate buffer saline; PBT, phosphate buffer saline with $0.8 \%$ TritonX-100; PFA, paraformaldehyde; Tü, Tübingen.
}

\footnotetext{
*Address correspondence to: Mahendra Sonawane. Department of Biological Sciences, Tata Institute of Fundamental Research, Colaba, Mumbai, India. Tel: 009122 22782707. E-mail: mahendras@tifr.res.in - (iD) https://orcid.org/0000-0002-1749-6247
}

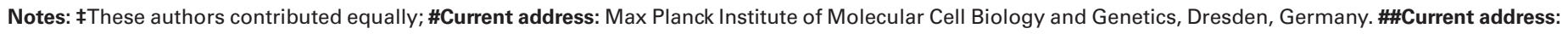
Centre for Neuroscience, Indian Institute of Science, Bengaluru, India. 
Peytavi et al., 2016; Coulombe et al., 2009).

As the epidermis experiences a constant pre-stress (Langer, 1861) combined with external mechanical assaults (Silver et al., 2003), several studies have analysed the in vivo response of the epidermis to mechanical stresses. These studies have shown that mechanical loading of the skin - either by spring based methods or inflating subcutaneous implants - adversely affects scar formation (Aarabi et al., 2007), causes breakdown of the subcutaneous microvasculature (Bader et al., 1986), and increases the thickness of cell layers (Squier, 1980; Zöllner et al., 2013) in the epidermis. However, the role of tension in shaping the developing bi-layered epidermal architecture has not been studied in vivo. Since early embryonic growth and morphogenetic movements are likely to exert tension on the overlying epidermis, it is important to characterise

A

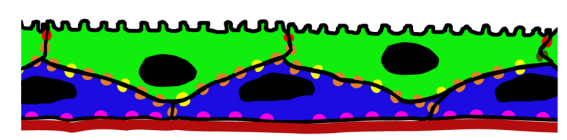

Periderm Basal Epidermis

Adherens Junctions Desmosomes Hemidesmosomes Basal Lamina Tight Junctions

B

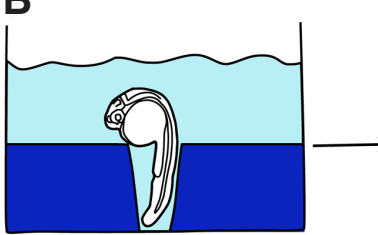

24 hpf embryos mounted vertically
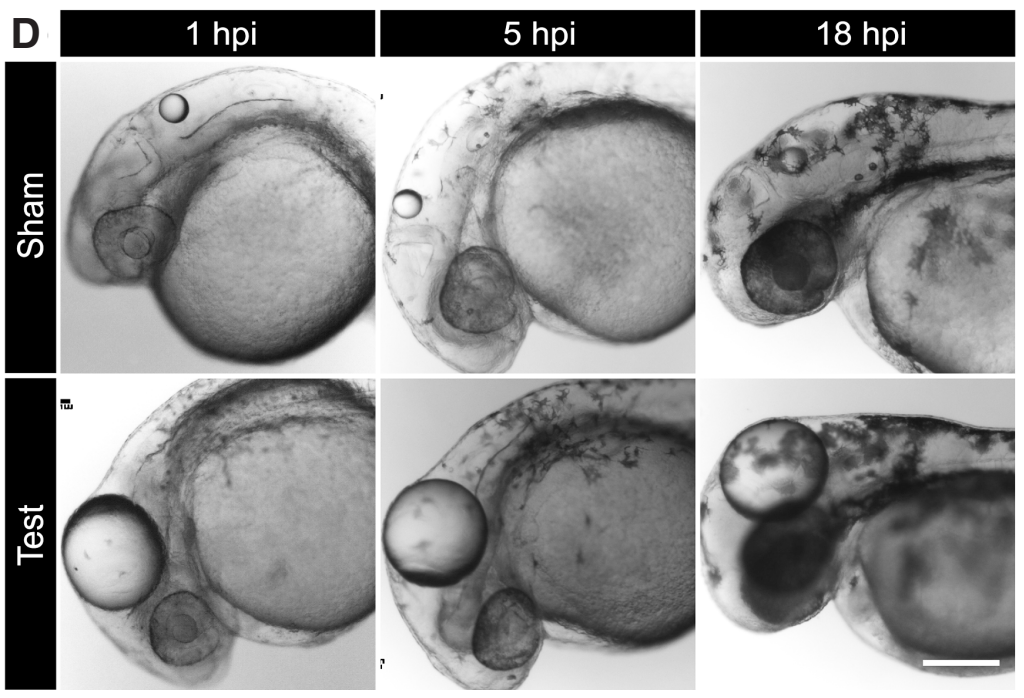

Fig. 1. Standardization of the oil injection paradigm. Schematic representation of bilayered zebrafish larval epidermis (A) and oil injection in the brain ventricle of $24 \mathrm{hpf}$ zebrafish embryos (B). Boxplot in (C) depicts the range of oil volumes ( $n L)$ tolerated by the embryonic epidermis at 24hpf in Tübingen and DBS strains before bursting $(N=3, n=21-34$ embryos). Bright field images of oil injected embryos (D), showing that the oil is maintained within the ventricle over development. Scale bar corresponds to $200 \mu m$, hpi, hours post injection. the epidermal response to tension and understand the molecular regulation behind such responses. The existing spring and implant based methods (Buganza Tepole et al., 2011; Squier, 1980) or other methods such as local micromanipulation by indentation, aspiration or magnetic beads - used to study stretch in epithelia (reviewed by Sugimura et al., 2015) - are difficult to apply in growing embryos. Although similar methods have been tried in model organisms (Farge, 2003; Schluck et al., 2013), mechanically stretching the developing epidermis in vivo has remained a non-trivial task. This necessitates the development of a simple in vivo paradigm that will allow manipulation of tension in the developing epidermis.

Numerous sensitive ways to detect the presence of mechanical stresses within epithelial cells and tissues have been established. These include, but are not restricted to, laser microdissections, liquid droplets and hydrogels, FRET based tension sensors, and atomic force microscopy (AFM) (Träber et al., 2018; Prange and Margulies, 2002; reviewed in Campàs, 2016). Each of these methods detect mechanical tension using different aspects of tissue behaviour. Non-invasive measurement of tension is possible using AFM, wherein a probe attached to a cantilever of a known spring constant is indented on the sample. The forces used for indentation can be used to obtain the elasticity modulus for the sample, which is a readout for the sample's resistance towards deformation or the tension experienced. Using AFM, tension can be measured in local, sub-cellular regions (reviewed in Kuznetsova et al., 2007) or at a tissue scale (Hunter et al., 2014; Wells et al., 2014) by varying the probe size. Recently, AFM has been used to show that developmental processes such as neural crest migration in Xenopus and ovarian follicle development in Drosophila depend on the stiffness of their substrates, mesoderm and basement membrane, respectively. (Chlasta et al., 2017; Barriga et al., 2018). Whether AFM can be used for quantifying tension in the developing embryonic epithelia has not been explored so far.

Here we present an in vivo paradigm involving injection of mineral oil in the brain ventricle to stretch the overlying embryonic epidermis in zebrafish embryos. We further report the standardisation of contact based AFM on live embryos and quantify the tension induced by the injected oil. Our analysis reveals that the epidermis responds to the imminent tension by cell expansion and increased cell proliferation. This method also unravels the importance of E-cadherin in tolerating tension in the developing epidermis.

\section{Experimental Protocols}

\section{Zebrafish handling and fish strains}

The experiments were done using wild-type strains of zebrafish (Tübingen, Tü) unless mentioned otherwise. DBS, a wild type strain developed in house, was also used as another wild-type strain to characterize variation in tolerance towards injection volumes. The analysis for cell cross-sectional area and cell proliferation was done using transgenic zebrafish line $\mathrm{Tg}$ (cldB:lynEGFP)(Haas and Gilmour, 2006). The embryos were grown at $29^{\circ} \mathrm{C}$, 
unless stated otherwise, and staged according to Kimmel et al., 1995. The fish husbandry and fixation protocols were approved by the Institutional Animal Ethics Committee via approval TIFR/ IAEC/2017-11.

\section{Microinjections}

The microinjections as well as ventricular injections were done using pneumatic picopump (PV830) and mechanical manipulator (M3301-M3-R) from World Precision Instruments. Capillary needles (BF100-50-10; Sutter Instruments) were pulled using P-97 micropipette puller (Sutter Instruments). The morpholinos were obtained from Gene Tools LLC and maintained as $1 \mathrm{mM}$ stocks in sterile water. Mosaic E-cadherin knockdown was achieved by microinjecting $50 \mu \mathrm{M}$ E-cadherin morpholino (5-ATCCCACAGTTGTTACACAAGCCAT-3') at 16-32 cell stage with tracer eGFP mRNA; a 5-bp mismatched morpholino (5'ATCCgACAcTTcTTACAgAAcCCAT3') was injected similarly as control (Knaut et al., 2005; Sonawane et al., 2009). The capped eGFP tracer RNA was transcribed from linearized pCS2 +8 eGFP construct using the SP6 mMessage mMachine kit (AM1340; Ambion).

\section{Brain-ventricular oil injections}

Brain-ventricular oil injections were developed by modifying the method used to study brain ventricle morphogenesis (Gutzman and Sive, 2009). Hydrophobic oil (Bio-Rad; 1632129) was injected, inflating the ventricle and stretching the overlying epidermis. The protocol, in detail, is as follows:

To prepare an injection mould $30 \mathrm{ml}$ of $3 \%(\mathrm{w} / \mathrm{v})$ Agarose (XcelGen; XGA-500) was poured in $90 \mathrm{~mm}$ petriplates (Tarsons; 460091) and allowed to solidify. $10 \mu \mathrm{L}$ tips (Tarsons; 521000) were used to punch holes in the agar bed, and the plate was filled with E3. The extra agar was cleaned out from the holes. 24 hour old dechorionated zebrafish embryos were anaesthetized using $0.02-0.024 \%$ tricaine in E3 and positioned vertically into the holes (Fig. 1B). A pulled capillary needle was broken to deliver 1-2 $n L$ volume per drop, in one injection timed for 10 seconds. The needle was positioned above the hind brain ventricle and used to carefully pierce the epidermis posterior to the midbrain-hind brain hinge point (Fig. 1B). To reduce the tissue damage, the angle of the needle was maintained as perpendicular to the head as possible. The same needle was used for an entire experiment. For each experiment, first 3 embryos were used to check the maximum oil volume tolerated by the embryos in that batch. 'Sham' embryos were injected with $0.1 \mathrm{~nL}$ oil (by adjusting the time of injection to 1 second) while 'Test' embryos received 14-17 nL (by injecting multiple drops, with each injection lasting for 10 second) oil unless stated otherwise (Fig. 1D). After injecting the requisite volume, the needle was retracted, and the embryo was removed from the hole. The test and sham injections were alternated to minimise the time difference between them.

\section{A}

B

\section{Brain ventricular injections combined with Atomic Force Microscopy (AFM)}

\section{Immobilization of embryos}

$90 \mathrm{~mm}$ petriplates were coated with $25 \mathrm{~mL}$ of $3 \%$ normal melting agarose, and divided into a $3 \times 3$ grid using a blade. The plate was flooded with E3 and the diagonally opposite parts of the grid were removed to obtain a '+' shaped agarose support (Fig 2A(i)). (i) Mounting embryos vertically for immobilization

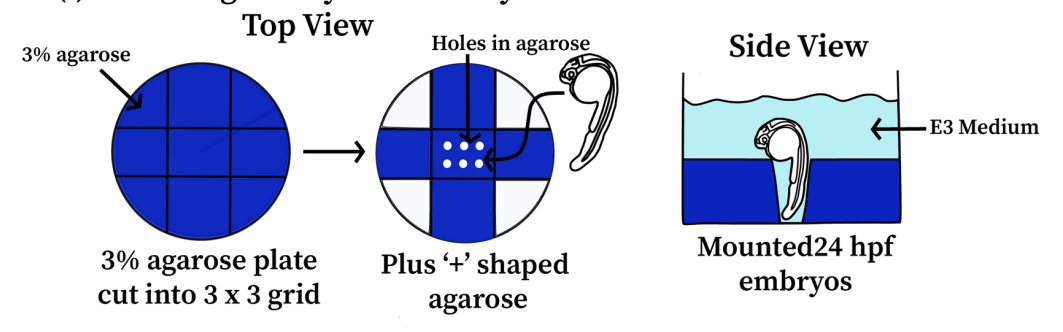

(ii) Immobilization of embryos

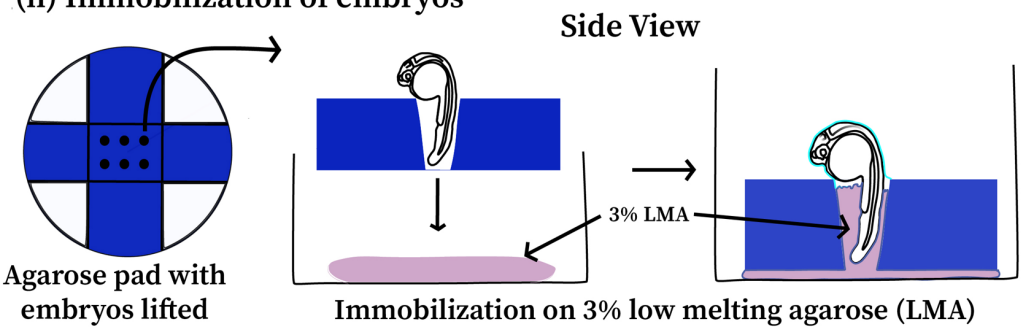

(iii) AFM readings with oil injection
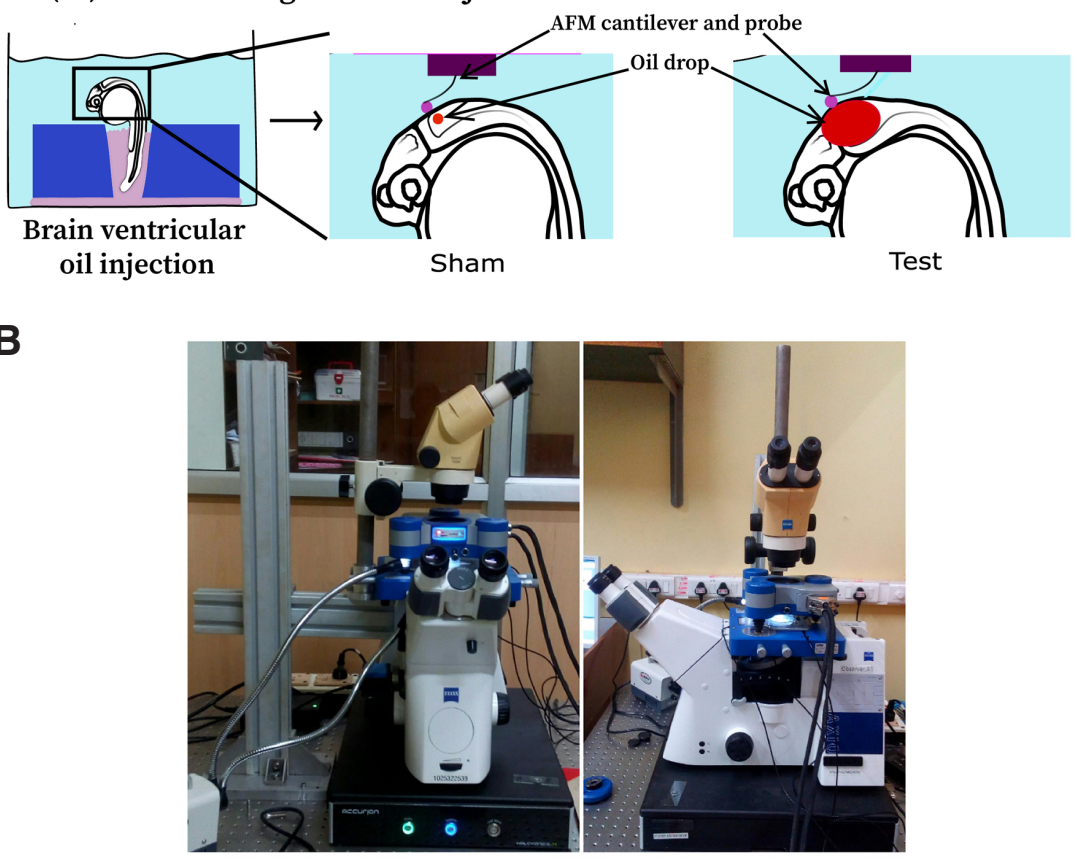

Fig. 2. Mounting of embryos for ventricular injections followed by atomic force microscopy (AFM). A schematic depiction (A) of the preparation of agarose plate to vertically mount (i) and immobilize 24 hpf zebrafish embryos using 3\% low melting agarose (LMA) (ii), followed by AFM measurements on the stretched region (iii). (B) The Zeiss Stemi 1000 Stereoscope coupled to JPK NanoWizard3 AFM system for the AFM measurements. 
Holes were made in the central part of the ' + ' shaped agarose and anesthetised embryos at 23-24 hpf were mounted in the holes, as stated in the earlier section. Excess E3 was carefully removed from the plate without dislodging the embryos (Fig 2A(ii)). The agarose pad with mounted embryos was gently lifted and placed on lukewarm 3\% low melting agarose in a separate $60 \mathrm{~mm}$ plate (Fig 2A(ii)). Due to capillary action, the low melting agarose filled the holes containing the embryos, immobilizing them. Filtered E3 medium was reintroduced to remove improperly immobilized embryos. Filtered medium is essential to avoid interference in AFM measurements by particulate matter. Upon successful embedding, we checked for embryo survival by looking at the heartbeat. The immobilized embryos were used for ventricular oil injections, as stated earlier.

\section{AFM indentation}

AFM experiments were done using NanoWizard 3 AFM system from JPK instruments with integrated CellHesion module to accommodate the piezo movements. The AFM system was mounted on Zeiss AxioObserver A1 inverted microscope. To visualise the embryos, the system was integrated with Zeiss Stemi 1000 stereoscope (Fig 2B). 20 4 m colloidal probes (HYDRA6V-200NG-TL-SiO-A, AppNano) with pre-attached cantilevers $(0.1 \mathrm{~N} / \mathrm{m}$ spring constant) were used for indentation. Each probe-cantilever pair was reused for up to 3 experiments, its spring constant calibrated to be within 0.09-0.06 N/m on glass and embryo medium before each experiment. Individual embryos were positioned under the cantilever using the stereoscope, such that the region above the midbrain-hindbrain hinge point could be indented $(5 \mu \mathrm{m} / \mathrm{s}, 1 \mathrm{nN}$ force setpoint, $0.5-2 \mu \mathrm{m}$ depth) (Fig 2A(iii)). Force measurements were taken in triplicates per embryo from an 8 X8 grid of points over a $2500 \mu \mathrm{m}^{2}$ area. The data was collected between 1 to 3 hours post ventricular injection at an ambient temperature of $23 \pm 1^{\circ} \mathrm{C}$.

\section{Analysis of force curves}

The force curves obtained from indentations were analysed using JPKSPM Data processing software (v-6.1.58). The extension curve of each force curve was processed using the software by first subtracting the baseline, followed by $x$-offset adjustment and correction of cantilever height. The processed curves were then fitted to the Hertz-Sneddon model configured in the software, and the value for Young's modulus for each curve was saved as a text file.

\section{Preparation of polyacrylamide gels}

Polyacrylamide gels were made as previously described (Krishnan et al., 2011). Briefly, glass slides were cleaned with fresh $0.1 \mathrm{~N} \mathrm{NaOH}$ followed by 5 minute activation with 4\% APTMS (3-aminopropyltrimethoxysilane) and 30 minute treatment with $1 \%$ glutaraldehyde. The slides were carefully rinsed with distilled water and air dried between each of these step. Gels of 4 different stiffness- $1 \mathrm{kPa}$ (5\% Acrylamide, $0.03 \%$ bis), $4 \mathrm{kPa}(5 \%$ Acrylamide, $0.1 \%$ bis), 6.3 $\mathrm{kPa}(10 \%$ Acrylamide, $0.03 \%$ bis), $11 \mathrm{kPa}(10 \%$ Acrylamide, $0.07 \%$ bis) were prepared and $40 \mu \mathrm{l}$ of the gel solution was added on the prepared slides and covered with a clean coverslip. The coverslip was removed once the gel polymerized at room temperature. The gels were stored in distilled water at $4^{\circ} \mathrm{C}$ prior to use.

\section{BrdU Incorporation assay}

To assess for proliferation, the $T g(c / d B$ :lynEGFP) line was used. Test and Sham embryos were incubated in $10 \mu \mathrm{M}$ BrdU solution in $2 \%$
DMSO (v/v in E3) for 2 or $3 \mathrm{~h}$. After the incubation, they were washed thrice in E3 for seven minutes each, followed by immediate fixation.

\section{Whole mount Immunostaining}

For whole mount immunostainings, zebrafish embryos were fixed overnight in 4\% PFA (w/v in PBS). To visualise the cell membrane using the $\mathrm{Tg}(\mathrm{cldB}$ :IynEGFP) transgenic line, the embryos were permeabilized in methanol at $-20^{\circ} \mathrm{C}$ overnight, followed by methanol downgrade and PBT washes (0.8\% Triton-X 100 in PBS). Post PBT washes, the embryos were blocked with $10 \%$ (v/v in PBT) Normal Goat Serum (05-000-121, Jackson Immuno Research Labs) for 3-4 hours, followed by overnight incubation in primary antibodies at $4^{\circ} \mathrm{C}$. This was followed by PBT washes and 4 hour incubation in secondary antibodies at room temperature. The embryos were again washed in PBT, post-fixed in 4\% PFA for 30 minutes and upgraded into glycerol for imaging. For BrdU staining, the embryos were permeabilized in methanol, downgraded to PBS and treated with $4 \mathrm{~N}$ $\mathrm{HCl}$ before the PBT washes. The antibodies used and their dilutions were anti-GFP (1:200; TP401, Torrey Pines Biolabs), anti-BrdU antibody (1:50; SM1667, Acris Antibodies), anti-E-cadherin antibody (1:100; 610182, BD Transduction Labs), Alexa fluor 488 conjugated anti-rabbit IgG (1:250; A11034, Invitrogen), Cy3 conjugated IgG anti-rabbit (1:750;111-165-144, Jackson ImmunoResearch Labs), anti-rat (1:750; 112-165-167, Jackson ImmunoResearch Labs) and anti mouse (1:750; 115-165-146, Jackson Immuno Research Labs).

\section{Image acquisition and processing}

Confocal images were taken in the dorsal region of the head using Zeiss LSM 510 Meta, Zeiss LSM 710, or Zeiss LSM 880. For the cell size analysis, Plan-apochromat $63 x / 1.40$ oil objective was used with 1.5x optical zoom. For cell proliferation, EC Plan-Neofluor 40x/1.30 oil objective was used with $1 \mathrm{x}$ optical zoom. For both, the image size was $1024 \times 1024$, with line averaging of 4 and 2 , respectively.

For visualising the oil drop over time, the embryos were anaesthetised with $0.02-0.024 \%$ tricaine in E3 and mounted using $0.5 \%$ low melting agarose to be imaged on Zeiss SteREO Discovery with AxioCam using $1 \mathrm{x}$ objective.

\section{Image analysis}

The images were analysed using ImageJ/ Fiji. The cell crosssectional area analysis was estimated by tracing the cell membrane at the apical-most slice of both peridermal and basal epidermal cells using the polygon tool in Fiji. The cell counter plugin in Fiji was used to count the number of BrdU positive cells in the periderm marked by membrane tagged GFP and normalized with the total number of peridermal cells to calculate the percentage of proliferating cells.

\section{Statistical analysis and graphs}

Mann-Whitney test for non-parametric distribution was used to compare the medians of the sets. A significance of 0.05 was used as a cut-off. SigmaPlot 13 and MaxStat Lite were used to perform the statistical analysis. BoxPlotR (http://shiny.chemgrid.org/boxplotr/) was used to generate the graphs.

\section{Results}

\section{Ventricular oil injection as a paradigm to stretch the overlying epidermis}

Epithelial response to mechanical stimuli has been studied in 
various contexts. However, barring a few exceptions (Borghi et al., 2012; Campinho et al., 2013), very few studies have used quantitative tools to study tension and its effect on developing vertebrate epithelia. This is possibly due to a lack of simple methods to induce tension in growing embryos. Therefore, we aimed at developing an in vivo paradigm using zebrafish embryos, to study how the epidermis responds to an increase in tension. The embryonic zebrafish epidermis is a bilayered tissue consisting of the outer peridermal layer and underlying basal epidermis (Fig 1A; Le Guellec et al., 2004; Sonawane et al., 2005). We modified the previously published protocol (Gutzman and Sive, 2009) to microinject mineral oil in the brain ventricle (Fig 1B; see methods for details). We hypothesized that inflating the ventricle would stretch the overlying epidermis. To begin with, we used two wild-type strains, Tübingen and DBS, to estimate the maximum oil volume that can be injected in the brain ventricle without rupturing the epidermis. We observed that stage-matched embryos showed a marked variation in tolerating injection volumes, from 7 to $30 \mathrm{~nL}$, in both the strains (Fig 1C). However, there was no significant difference (Fig. 1C; Mann Whitney test, $\mathrm{P}>0.1$ ) between the volumes tolerated by Tübingen and DBS strain suggesting that this tolerance to stretch is not strain specific. We excluded the clutches with very low tolerance $(<14 \mathrm{~nL}$ ) from analyses reported hereafter. Typically, injection of $14-17 \mathrm{~nL}$ of oil at $24 \mathrm{hpf}$ inflated the ventricle, creating the test condition and injection of $0.1 \mathrm{~nL}$ oil served as a sham control (Fig 1D). The test and sham injections were alternated to minimise the time difference between them. After injection, the embryos were observed to check for viability, and not considered for further analyses if they showed: (a) oil oozing from the injection site (b) accumulation of cells around the site of injection (c) necrosis around the tail or yolk or (d) that the oil drop penetrates the neural tissue. These deleterious post-injection effects could be detected either immediately or by 4-5 hours post injection (hpi). However, in most injections, the injected oil was retained in the brain ventricle for $18 \mathrm{hpi}$ (Fig. 1D) and, when grown beyond, even up to 3 days post injection (data not shown).

To conclude, we modified the existing paradigm used to study brain ventricle morphogenesis for inducing mechanical stretch in the developing zebrafish epidermis.

\section{Estimation of tension in the developing epidermis upon ventricular oil injection using AFM}

While ventricular injections result in epidermal stretch, the extent of tension generated upon such injections remained unknown. For this, we aimed at obtaining a quantitative readout for the increased tissue tension in the form of elastic or Young's modulus using AFM.

To use AFM on live embryos, we first standardized a method for immobilization. Briefly, we mounted embryos vertically in holes made in 3\% agarose, immobilized them using $3 \%$ low melting agarose, followed by ventricular injections (Fig 2A; see methods for details). For force measurements, we used a customized JPK NanoWizard 3 AFM setup which allowed visualisation of embryos (Fig 2B).

As a reference, we measured the Young's modulus of polyacrylamide (PAA) gels of known stiffness using AFM. We prepared PAA gels of 1, 4, 6.3 and $11 \mathrm{kPa}$ stiffness, as determined previously by bulk deformation experiments (Krishnan et al., 2011; Lee et al., 1994). Our AFM based force measurements yielded 0.35-0.7 times lower values for Young's modulus than the previously reported estimations by bulk deformation (Fig 3A). However, the Young's modulus increased as the stiffness of PAA gels increased (Fig $3 A$ ), suggesting that AFM effectively detects relative changes in stiffness.

For AFM analysis on embryos, the test and sham animals were injected with 14-17 $\mathrm{nL}$ and $0.1 \mathrm{~nL}$ oil, respectively. A $2500 \mu \mathrm{m}^{2}$ region above the midbrain-hindbrain hinge point was indented in both tests and shams. This analysis showed that the Young's modulus for test embryos (88.1 $\pm 27 \mathrm{~Pa})$ was 1.5-to-2 fold higher than that for shams $(38.7 \pm 15 \mathrm{~Pa})$, suggesting that the embryos subjected to ventricular oil injections experience higher tension in the epidermis (Fig 3B; Mann Whitney test, ${ }^{* *} P<0.001$ ). We also tested if the volume of injected oil alters the Young's modulus, by injecting oil volumes ranging from 1 to $17 \mathrm{~nL}$. We observed that for this range of injection volumes, the Young's modulus increases in a linear fashion (Fig. 3C).
A

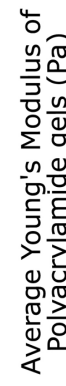

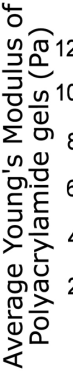

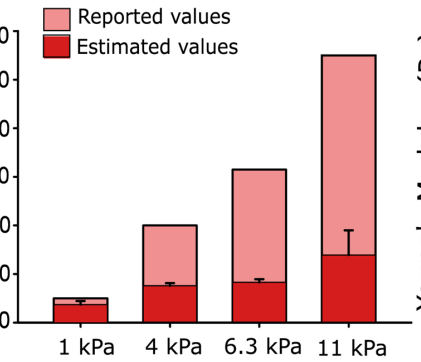

C

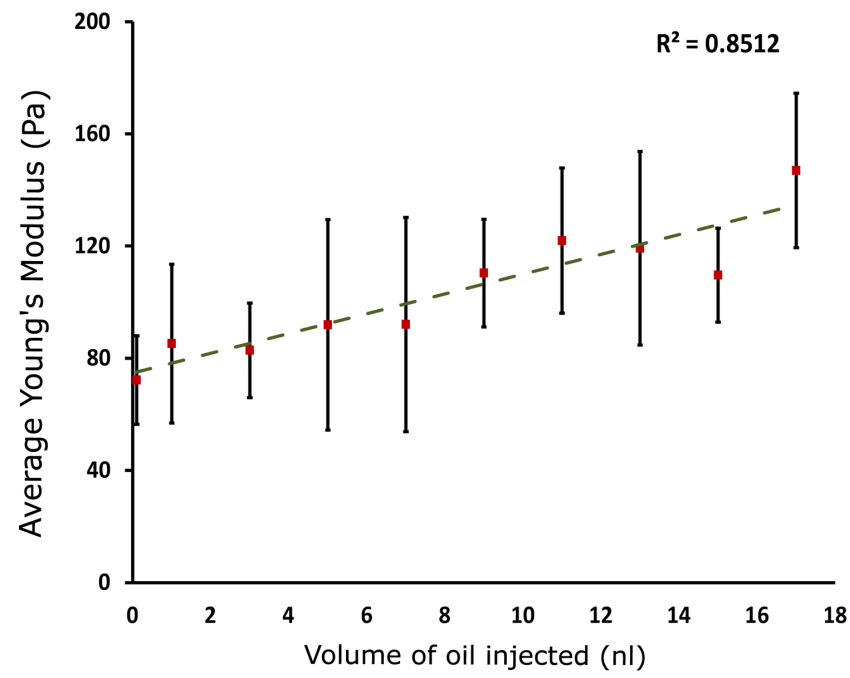

Fig. 3. Estimating tension in the embryonic epidermis upon oil injection. Bar graph presenting average Young's modulus obtained for gels of varying stiffness using AFM, superimposed on the reported values for the gels (A) ( $N=3, n=3-4$ gels). Boxplot (B) depicting significant increase in Young's modulus in test embryos as compared to sham. ( $N=3, n=4-5$ embryos; ** $\mathrm{P} \leq 0.001$, Mann-Whitney Rank Sum test). Regression analysis (C) shows linear increase in average Young's modulus with respect to the volume of oil injected. ( $N=4-9$ embryos per volume). Error bars indicate standard error in (A) and standard deviation in (C). 
From this analysis, we conclude that AFM is an excellent method to quantify the relative increase in tension experienced by the epidermis under the oil injection paradigm.

\section{Tension induced by ventricular oil injection is enough to invoke tissue response}

Epithelia have been shown to respond to mechanical stretch by modulating features such as cellular aspect ratio, cell size and cell proliferation (Squier, 1980; Tokuyama et al., 2015; Truschel et al., 2002; Zöllner et al., 2013). Since our AFM analysis revealed an increase in tension in the epidermis upon injection of mineral oil, we probed if this increased tension elicits a tissue response, by analysing changes in cell cross-sectional area and proliferation in the epidermis post oil-injection.

To characterise changes in cell cross-sectional area, we used a transgenic line that labels the cell membranes of peridermal cells
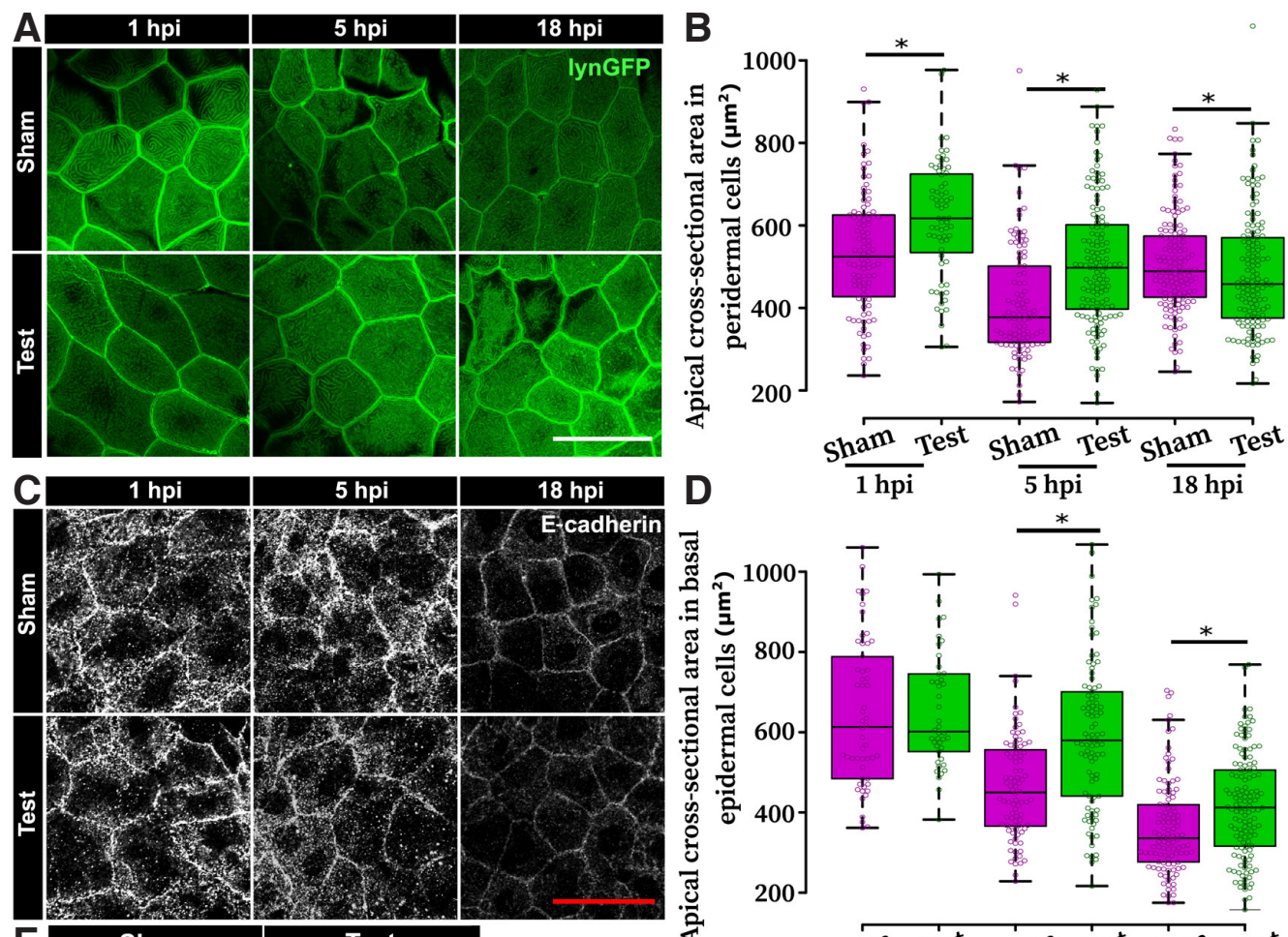

$\mathbf{E}$
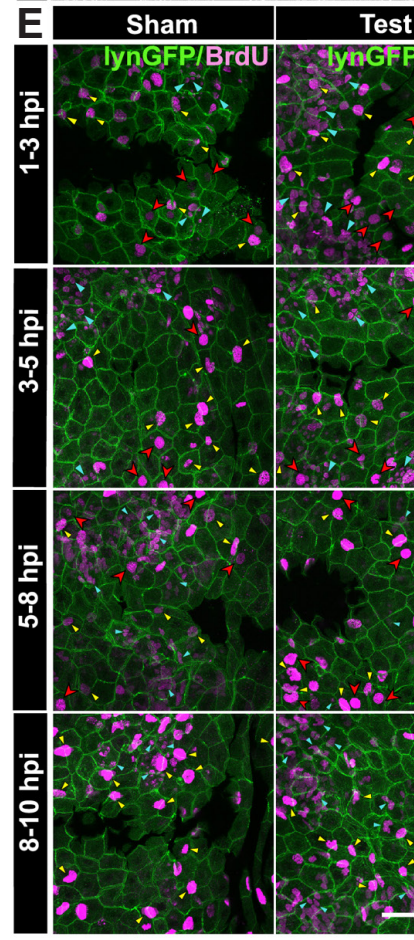

TEFF/Broly
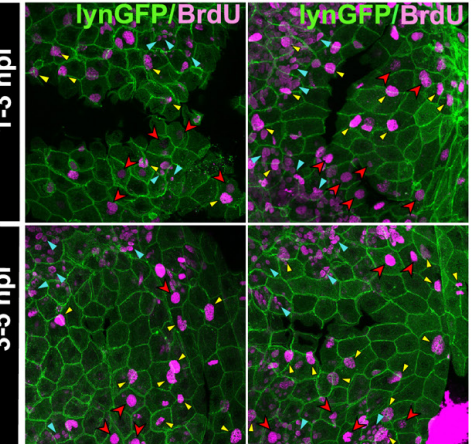

$\mathbf{F}$

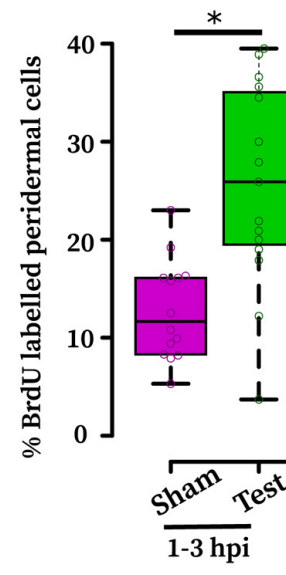

$\frac{\text { sham Test sham Test }}{1 \mathrm{hpi}} \frac{\mathrm{sham}^{\mathrm{Thpi}}}{\frac{\mathrm{h}}{18 \mathrm{hpi}}}$
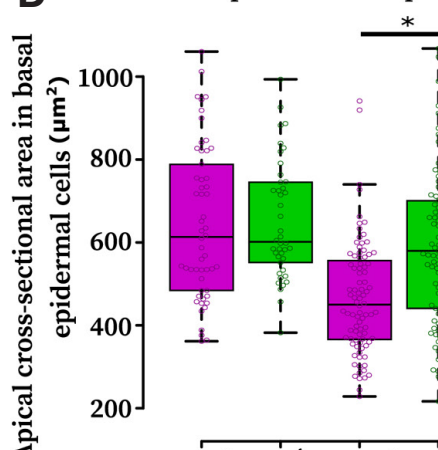

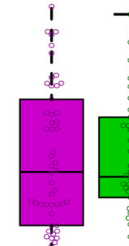

$+$

然
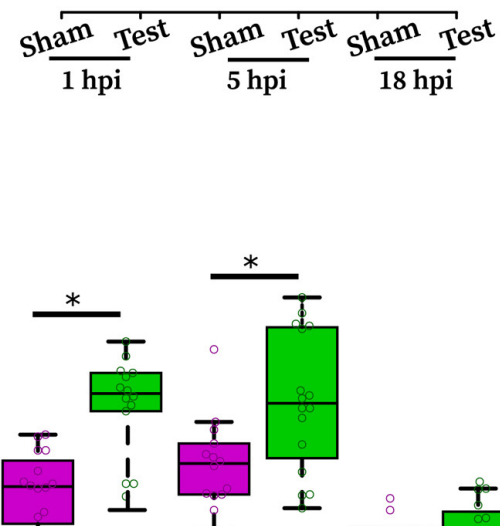

i

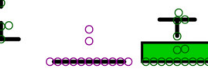

\section{(a)}

5 hat shate

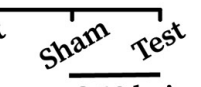

Fig. 4. Tissue response in the epidermis under stretch. Confocal micrographs of lynGFP (A) and E-cadherin (C) stainings and the quantification of cell cross-sectional area $(\mathbf{B}, \mathbf{D})$ reveal the effect of stretch on the peridermal cells $(\mathbf{A}, \mathbf{B})$ and basal epidermal cells $(\mathbf{C}, \mathbf{D})$ in test embryos as compared to sham ( $N=4, n=60-140$ cells for the periderm; $N=3, n=42-130$ cells for the basal epidermis; ${ }^{*} P \leq 0.05$; MannWhitney Rank Sum test). Analysis of peridermal cell proliferation $\mathbf{( E}$, F) using BrdU incorporation assay shows an immediate increase in cell cycle entry under stretch. Confocal micrographs of embryos stained for lynGFP (green) and BrdU (magenta) in sham and test embryos at various time-points after oil injection (E) and quantification of labelled cells (F) ( $N=3, n \geq 28$ embryos; * $\mathrm{P} \leq 0.05$; Mann-Whitney Rank Sum test). Note that periderm specific expression of lynGFP was used to distinguish between BrdU labelled peridermal (red arrowhead) and basal epidermal cells (yellow arrowhead). Non-epithelial BrdU labelled nuclei are represented with blue arrowheads. Scale bar corresponds to $40 \mu \mathrm{m}$ in $(A, C)$ and $100 \mu \mathrm{m}$ in (E). 
by expressing Lyn-tagged GFP under claudin $b$ promoter (Haas and Gilmour, 2006). The cross-sectional area of the peridermal and basal epidermal cells was analysed at- $1 \mathrm{hpi}$ (immediate response), 5 hpi (intermediate response) and $18 \mathrm{hpi}$ (chronic response). The embryos fixed at the respective time points were immunostained for membrane-bound GFP and E-cadherin to probe for changes in the cross-sectional area in both periderm as well as basal epidermis. We observed that in the periderm, the apical cell cross-sectional area increased in the test embryos at 1 and 5 hpi when compared to the sham embryos, but was significantly reduced at $18 \mathrm{hpi}$ (Fig 4 A,B; Mann Whitney test, $\left.{ }^{*} P \leq 0.05\right)$. In the basal epidermis, the cross sectional area in test embryos displayed no significant difference from the sham embryos at $1 \mathrm{hpi}$. However, at $5 \mathrm{hpi}$ and 18hpi the test embryos showed significant increase in the cross-sectional area of basal epidermal cells (Fig 4 C,D), Mann Whitney test, $\left.{ }^{*} P \leq 0.05\right)$. This difference arises as a consequence of developmental reduction in cross-sectional area of the basal epidermal cells in the sham embryos between 1 and 5 hpi while the cells in the test embryos remain refractory to these changes due to increased tension. Thus, both the epidermal layers respond to ventricular oil injections by either increasing cross-sectional area or by not allowing the developmental decrease in cell crosssectional area to occur.

Both the epidermal layers in the test embryos show a recovery in their apical cross-sectional area over time (Fig.4 B, D) suggesting that the epidermal response is temporally regulated to regain homeostatic cell size. Since cell proliferation has been shown to increase in a response to stretch in the epidermis (Squier, 1980; Tokuyama et al., 2015; Zöllner et al., 2013), we hypothesized that increased cell number via cell proliferation may be responsible for this recovery. Following the BrdU incorporation assay, we analysed proliferation in the periderm - marked by membrane tagged GFP - by counting for BrdU labelled nuclei. We found that there is an immediate increase (1-3 hpi) in the percentage of proliferating cells in the periderm upon stretch, which continues up to 8 hpi (Fig 4 E,F; Mann Whitney test, $\left.{ }^{\star} P \leq 0.05\right)$. This increased BrdU labelling in the periderm under stretch shows an increased commitment towards proliferation, culminating into increased cell number and reduced cell cross-sectional area at later time points.

To conclude, increased tension upon oil injection is sufficient to invoke a typical stretch response characterised by the increase in cell cross-sectional area and cell proliferation in the epidermis. This ventricular injection paradigm also allows analysis of the early as well as long term tissue responses to stretch.

\section{The ventricular oil injection paradigm unravels the importance of E-cadherin in sustaining tension}

Presence of strong adhesive forces are essential to sustain mechanical stresses and maintain tissue integrity in epithelia (Ray et al., 2013; Raghavan et al., 2000; Georges-Labouesse et al., 1996; Sonawane, 2005). Furthermore, in vitro analyses shows that under stretch, the epidermis responds by increasing cell-cell and cell-matrix adhesion (Tokuyama et al., 2015; Knies et al., 2006). To further assess the utility of our paradigm in evaluating tissue resilience under mechanical stretch, we tested it on embryos with reduced cell-cell adhesion. We knocked down E-cadherin, a transmembrane component of adherens junctions, in a mosaic manner, using a highly specific morpholino (Knaut et al., 2005; Sonawane et al., 2009). The clones were labelled by co-injecting GFP mRNA along with the morpholino. We selected embryos showing epidermal clones above the hindbrain ventricle, and subjected them to stretch using ventricular oil injections (Fig 5A). We observed that the epidermis in these embryos is easily fractured upon injection of more than 10-11 nL oil compared to control embryos. Interestingly, in embryos possessing E-cadherin deficient clones, injection of a sustainable volume of 7-10nLoil deformed the overlying epidermis, unlike the controls. This deformation progressively worsened over time, eventually fracturing the epidermis, as seen by observing individual embryos post oil injection (Fig 5D; phenotype observed in - cdh $1 \mathrm{MO}$ shams $=0 / 13$, control $\mathrm{MO}$ test $=3 / 18$, cdh $1 \mathrm{MO}$ test $=14 / 26, N=4)$. Live tracking of the E-cadherin deficient clones under stretch at 2 hour intervals showed loss of morphant cells (Fig 5 Bv,vi), possibly through extrusion (Fig 5C), prior to deformation. Such a selective extrusion and deformation was absent in both- the test embryos injected with control morpholino and the sham embryos with mosaic e-cadherin knockdown (Fig $5 \mathrm{Bi}$-iv), suggesting that this is not a consequence of either stretch or $e$ cadherin knockdown alone, but a combination of both.

We conclude that the oil injection paradigm can be used to assess the importance of genes regulating cell-cell or cell-matrix adhesion in tolerating tissue tension. Our data also indicate that $\mathrm{E}$-cadherin levels become relevant in the epidermis only under mechanical stress. E-cadherin does not seem to be essential in sustaining the inherent tissue tension.

\section{Discussion}

Epidermal response to tension has been discussed previously in multiple contexts but due to the difficulty in manipulating the epidermis in vivo, the molecular mechanisms underpinning these responses have remained poorly understood. Here, we report an easy paradigm to stretch the growing embryonic epidermis and establish the utility of AFM in quantifying tissue tension in live embryos.

OurAFM measurements show that injection of 14-17nLoil results in a discernible increase in the tissue tension in the developing epidermis. Furthermore, the increase in tension is linearly related to the injection volume. The Young's moduli we show here for the embryonic epidermis are significantly lower than those reported for keratinocytes in vitro. However, they are similar to Young's moduli reported for other embryonic structures such as the primitive streak (50-400 Pa) and the chick embryonic gut (20-200 Pa)(Chevalier et al., 2016; Henkels et al., 2013; Levental et al., 2007). It is also important to note that we see a significant difference between the Young's moduli obtained using AFM (our analyses) and bulk deformation (Pelham and Wang, 1997) for polyacrylamide gels of high stiffness. While these differences may be attributed to different techniques of measurement or conditions of polymer preparation (Denisin and Pruitt, 2016), we cannot rule out the possibility that the actual tension in the epidermis is higher than our reported values. Nevertheless, AFM is an effective method to measure relative changes in tension in the epidermis under various genetic and chemical perturbations.

It has been shown that cell shape and size in an epithelial sheet are intimately correlated with the tension experienced by cells (LeGoff et al., 2013; reviewed in LeGoff and Lecuit, 2016; Schluck et al., 2013). We observe that in zebrafish, the periderm responds to stretch by an immediate increase in cell cross-sectional area 
( $1 \mathrm{hpi}$ ). This increase in cell cross-sectional area - potentially by remobilising membrane reservoirs (reviewed in Figard and Sokac, 2014; Truschel et al., 2002) - may help the epidermis buffer the increased tension. On the other hand, the inner basal epidermis shows a similar effect on cross-sectional area at 5 hpi by acting

A

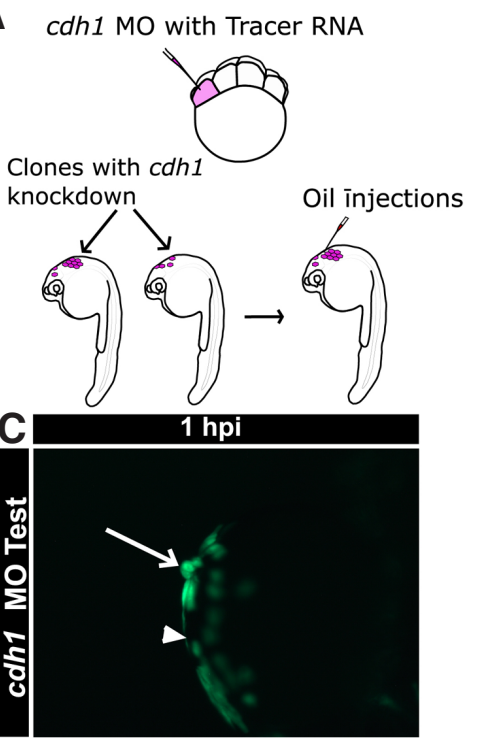

D

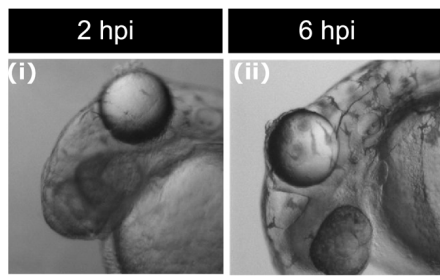

$\mathbf{E}$
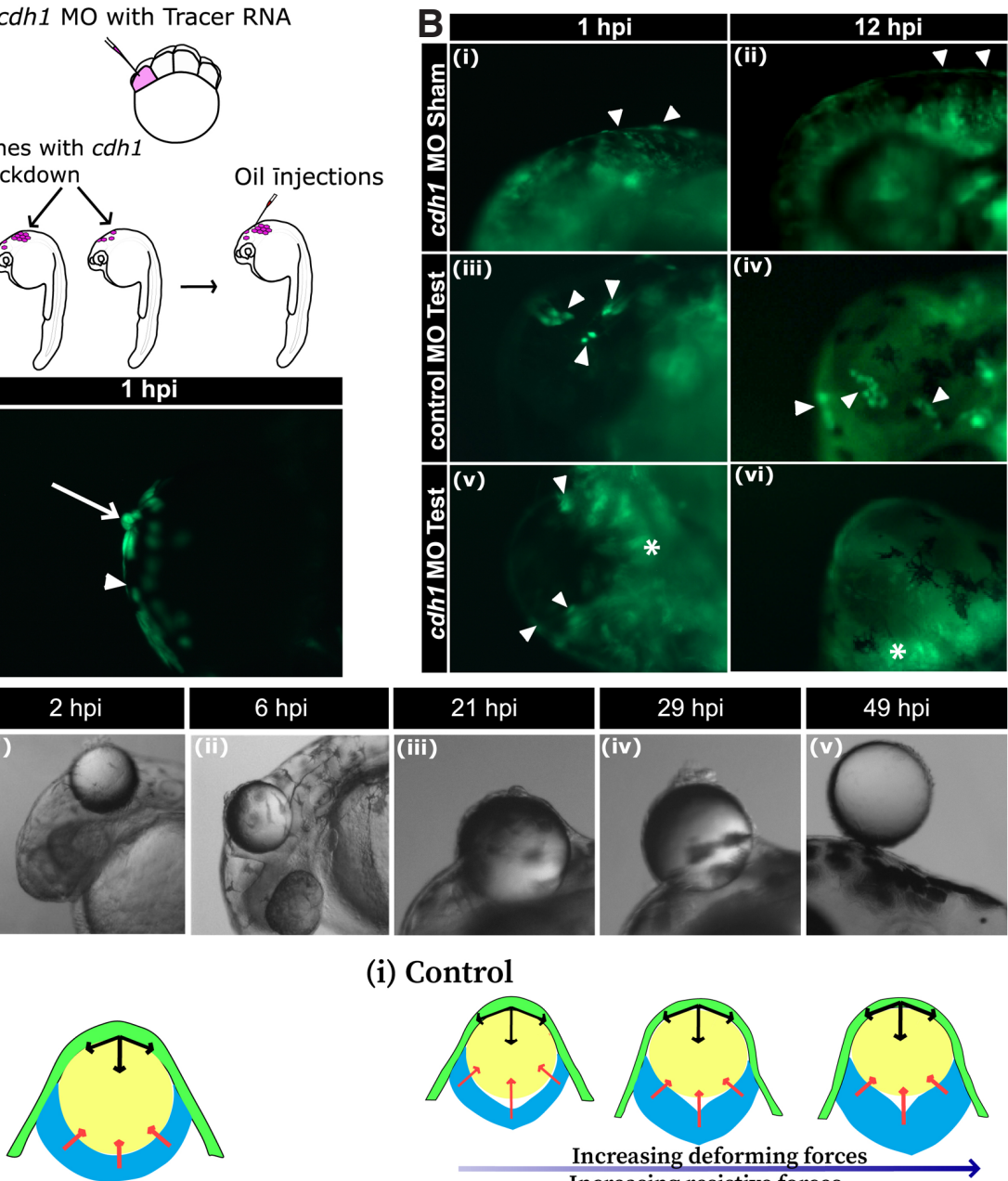

Oil drop

Epidermis

Neuroepithelium

Local weakness due to loss of cells

Cells with E-cadherin knockdown

$\rightarrow$ Resistive forces from the epidermis

$\rightarrow$ Deforming forces from the underlying neural tissue (ii) E-cadherin knockdown

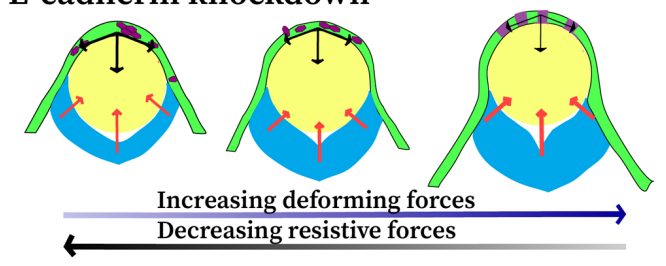

refractory towards acquiring smaller size during development. The 'delayed' response in the basal epidermis could be a consequence of low adhesion in the basal epidermal cells at $25 \mathrm{hpf}$ ( $1 \mathrm{hpi})$, allowing the cells to reorganise better to accommodate the immediate stretch. However, by $5 \mathrm{hpi}$, the basal cells presumably have established better cell-cell contacts resulting in decreased plasticity and remain refractory to a decrease in cross-sectional area.

Does increased apoptosis contribute towards the increase in cell cross sectional area in the periderm upon the induction of tension? Our live imaging analysis of sham and test embryos, immediately following the oil injections, did not show significant presence of cell-rosettes (Chouhan and Sonawane, unpublished observations) that are typically present upon cell death and delamination. These preliminary observations suggest that minimal apoptosis takes place due to the increased tension applied to the tissue. It is thus unlikely that a decrease in the number of cells due to increased apoptosis contributes towards the expansion of epidermal cells upon induction of tension.

When subjected to tensile stress, the epidermal histological architecture recovers over time (Squier, 1980; Zöllner et al., 2013), and this recovery coincides with increased mitotic index (Lorber and Milobsky, 1968; Squier, 1980; Tokuyama et al., 2015). We also report a similar recovery in cell cross-sectional area under sustained stretch, coinciding with increased cell proliferation. This increase in cell division has been suggested to help relieve tension anisotropy and dissipate tension in stretched epithelial sheets (Campinho et al., 2013; Wyatt et al., 2015; Xu et al., 2016). It is likely that the increased proliferation and the consequent recovery in cell cross-sectional area, helps the epidermis in tolerating the tensile stress.

Apart from increased cell number, junctional rearrangements and increased cell adhesion have been shown to dissipate tension (reviewed in Pinheiro and Bellaïche, 2018). It is also known that in the absence of proper cell-cell/cell-matrix adhesion, cytoskeletal organisation and extracellular matrix support, the epidermis is unable to tolerate mechanical forces (Georges-Labouesse et al., 1996; Lyu et al., 2016; Raghavan et al., 2000; Ray et al., 2013; Reis et al., 1994; Varki et al., 2007). Collective loss of P-cadherin and $\mathrm{E}$-cadherin function in the epidermis results in cell detachments, blistering and loss of barrier function in mice (Tinkle et al., 2008). However, the loss of E-cadherin alone does not result in perturbed epidermal integrity (Tinkle et al., 2004; Young etal., 2003) despite the reports that such a loss inhibits formation of tight junctions (Tunggal et al., 2005) and cell-cell junctions (Capaldo and Macara, 2007). Our analyses presented here
Fig. 5. E-cadherin maintains tissue integrity under tension. A schematic to depict mosaic e-cadherin (cdh1) knockdown and selection of embryos for oil injection (A). Live imaging of GFP labelled clonal cells $(\mathbf{B}, \mathbf{C})$ in given genetic conditions at $1 \mathrm{hpi}$ and $12 \mathrm{hpi}$ reveals that cdh 1 knockdown clones are lost from the epidermis under stretch. White arrowheads point to the GFP labelled clonal cells in (B,C), white asterisk labels the non-epidermal GFP positive clones in (B), and a white arrow point to an extruding cell in (C). The bright field images of an embryo carrying e-cadherin morphant clones (D) at 100x (i, ii) and 150x (iii, iv, v) magnification, showing gradual epidermal deformation over time and release of the oil drop. A schematic (E) depicting the balanced forces in the epidermis after oil injection in control morpholino injected embryos (E-i). Imbalance between these forces, upon cdh1 knockdown, results in extrusion of oil drop from the ventricle (E-ii). 
indicate that E-cadherin function is indeed dispensable for cell adhesion as the $\mathrm{E}$-cadherin morphant clones are retained without any obvious loss of integrity in the absence of external forces. On the contrary, the morphant cells with low E-cadherin levels are lost from the stretched epidermis, indicating the importance of E-cadherin mediated adhesion in sustaining increased tension. This loss of cells presumably weakens the epidermis, allowing the forces from the oil drop, cerebrospinal fluid secretion and brain morphogenesis to deform it (Fig 5E).

Zebrafish is a valuable vertebrate model to investigate the mechanisms underlying the maintenance of epidermal architecture and integrity (Carney et al., 2010; Feitosa et al., 2012; Hatzold et al., 2016; Jänicke et al., 2010; Lee et al., 2014; Raman et al., 2016; Reischauer et al., 2009; Slanchev et al., 2009; Sonal et al., 2014; Sonawane et al., 2005, 2009). Here we report a novel paradigm that can be used to decipher the mechanisms underlying stress tolerance in the vertebrate epidermis. Our results for E-cadherin depletion suggest that this paradigm would yield novel insights when combined with genetic and chemical perturbations, expanding our current understanding of mechanical regulation of tissue growth and maintenance. This oil injection paradigm can also be modified to stretch other embryonic regions such as yolk, notochord, optic cup and otic vesicle in zebrafish. In addition, the protocols established here, for oil injections or AFM measurements, can be easily adapted to other organisms like Xenopus and chick and thus have a wider applicability.

\section{Acknowledgements}

We thank Dr. Tamal Das and P. Phani Shilpa at TIFR Hyderabad for providing guidance for the experiments with polyacrylamide gels, Dr. Kalidas Kohale at TIFR for fish facility maintenance, and Shivali Dongre for critically reading the manuscript. We acknowledge funding from Department of Atomic Energy - TIFR to MS and SRK.

\section{References}

AARABI S, BHATT KA, SHI Y, PATERNO J, CHANG EI, LOH SA, HOLMES JW, LONGAKER MT, YEE H, GURTNER GC (2007). Mechanical load initiates hypertrophic scar formation through decreased cellular apoptosis. FASEB J 21: 3250-3261.

BADER DL, BARNHILL R, RYAN T (1986). Effect of externally applied skin surface forces on tissue and vasculature. Arch Phys Med Rehabil 67: 807-811. https:// www.archives-pmr.org/article/0003-9993(86)90160-7/pdf

BARRIGA EH, FRANZE K, CHARRAS G, MAYOR R (2018). Tissue stiffening coordinates morphogenesis by triggering collective cell migration in vivo. Nature 554: 523-527. http://dx.doi.org/10.1038/nature25742.

BLUME-PEYTAVI U, TAN J, TENNSTEDT D, BORALEVI F, FABBROCINI G, TORRELO A, SOARES-OLIVEIRA R, HAFTEK M, ROSSI AB, THOUVENIN MD, et al., (2016). Fragility of epidermis in newborns, children and adolescents. J Eur Acad Dermatology Venereol 30: 3-56.

BORGHI N, SOROKINA M, SHCHERBAKOVA OG, WEIS WI, PRUITT BL, NELSON WJ, DUNN AR (2012). E-cadherin is under constitutive actomyosin-generated tension that is increased at cell-cell contacts upon externally applied stretch. Proc Natl Acad Sci USA 109: 12568-12573.

BUGANZA TEPOLE A, JOSEPH PLOCH C, WONG J, GOSAIN AK, KUHL E (2011). Growing skin: A computational model for skin expansion in reconstructive surgery. J Mech Phys Solids 59: 2177-2190.

CAMPÀS O (2016). A toolbox to explore the mechanics of living embryonic tissues. Semin Cell Dev Biol 55: 119-130.

CAMPINHO P, BEHRNDT M, RANFT J, RISLER T, MINC N, HEISENBERG CP (2013). Tension-oriented cell divisions limit anisotropic tissue tension in epithelial spreading during zebrafish epiboly. Nat Cell Biol 15: 1405-1414.

CAPALDO CT, MACARA IG (2007). Depletion of E-Cadherin Disrupts Establishment but Not Maintenance of Cell Junctions in Madin-Darby Canine Kidney Epithelial Cells. Mol Biol Cell 18: 189-200.

CARNEY TJ, FEITOSA NM, SONNTAG C, SLANCHEV K, KLUGER J, KIYOZUMI D, GEBAUER JM, TALBOT JC, KIMMEL CB, SEKIGUCHI K, WAGENER R, SCHWARZ H, INGHAM PW, HAMMERSCHMIDT M (2010). Genetic analysis of fin development in zebrafish identifies furin and Hemicentin1 as potential novel fraser syndrome disease genes. PLoS Genet 6: e1000907.

CHEVALIER NR, GAZGUEZ E, DUFOUR S, FLEURY V (2016). Measuring the micromechanical properties of embryonic tissues. Methods 94: 120-128.

CHLASTA J, MILANI P, RUNEL G, DUTEYRAT J, ARIAS L, LAMIRE L, BOUDAOUD A, GRAMMONT M (2017). Variations in basement membrane mechanics are linked to epithelial morphogenesis. Development: 4350-4362.

COULOMBE PA, KERNS ML, FUCHS E (2009). Epidermolysis bullosa simplex: a paradigm for disorders of tissue fragility. J Clin Invest 119: 1784-1793.

DENISIN AK, PRUITT BL (2016). Tuning the Range of Polyacrylamide Gel Stiffness for Mechanobiology Applications. ACS Appl Mater Interfaces 8: 21893-21902.

FARGE E (2003). Mechanical Induction of Twist in the Drosophila Foregut/Stomodeal Primordium. Curr Biol 13: 1365-1377.

FEITOSA NM, ZHANG J, CARNEY TJ, METZGER M, KORZH V, BLOCH W, HAMMERSCHMIDT M (2012). Hemicentin 2 and Fibulin 1 are required for epidermaldermal junction formation and fin mesenchymal cell migration during zebrafish development. Dev Biol 369: 235-248.

FIGARD L, SOKAC AM (2014). A membrane reservoir at the cell surface. Bioarchitecture 4: 39-46.

GEORGES-LABOUESSE E, MESSADDEQ N, YEHIA G, CADALBERT L, DIERICH A, LE MUER M (1996). Absence of integrin alpha6 leads to epidermolysis bullosa and neonatal death in mice. Nat Genet 13: 370-373.

LE GUELLEC D, MORVAN-DUBOIS G, SIRE JY (2004). Skin development in bony fish with particular emphasis on collagen deposition in the dermis of the zebrafish (Danio rerio). Int J Dev Biol 48: 217-231.

GUTZMAN JH, SIVE H (2009). Zebrafish Brain Ventricle Injection. J Vis Exp: 3-5.

HAAS P, GILMOURD (2006). Chemokine Signaling Mediates Self-Organizing Tissue Migration in the Zebrafish Lateral Line. Dev Cell 10: 673-680.

HATZOLD J, BELEGGIA F, HERZIG H, ALTMÜLLER J, NÜRNBERG P, BLOCH W, WOLLNIK B, HAMMERSCHMIDT M (2016). Tumor suppression in basal keratinocytes via dual non-cell-autonomous functions of a Na,K-ATPase beta subunit. Elife 5: e14277.

HENKELS J, OH J, XU W, OWEN D, SULCHEK T, ZAMIR E (2013). Spatiotemporal mechanical variation reveals critical role for rho kinase during primitive streak morphogenesis. Ann Biomed Eng 41: 421-432.

HUNTER GL, CRAWFORD JM, GENKINS JZ, KIEHART DP (2014). Ion channels contribute to the regulation of cell sheet forces during Drosophila dorsal closure. Development 141: 325-334.

JÄNICKE M, RENISCH B, HAMMERSCHMIDT M (2010). Zebrafish grainyhead-like1 is a common marker of different non-keratinocyte epidermal cell lineages, which segregate from each other in a Foxi3-dependent manner. Int J Dev Bio/54:837-850.

KIMMEL CB, BALLARD WW, KIMMEL SR, ULLMANN B, SCHILLING TF (1995). Stages of Embryonic-Development of the Zebrafish Stages of Embryonic Development of the Zebrafish. Dev Dyn 203: 253-310.

KNAUT H, BLADER P, STRÄHLE U, SCHIER AF (2005). Assembly of trigeminal sensory ganglia by chemokine signaling. Neuron 47: 653-666.

KNIESY, BERNDA, KAUFMANNR, BEREITER-HAHNJ, KIPPENBERGERS (2006). Mechanical stretch induces clustering of $\beta 1$-integrins and facilitates adhesion. Exp Dermatol 15: 347-355.

KOSTER MI, ROOP DR (2007). Mechanisms Regulating Epithelial Stratification. Annu Rev Cell Dev Biol 23: 93-113.

KRISHNAN R, KLUMPERS DD, PARK CY, RAJENDRAN K, TREPAT X, VAN BEZU J, VAN HINSBERGH VWM, CARMAN C V., BRAIN JD, FREDBERG JJ, BUTLER JP, VAN NIEUW AMERONGEN GP (2011). Substrate stiffening promotes endothelial monolayer disruption through enhanced physical forces. AJP Cell Physiol 300: C146-C154.

KUZNETSOVA TG, STARODUBTSEVA MN, YEGORENKOV NI, CHIZHIK SA ZHDANOV RI (2007). Atomic force microscopy probing of cell elasticity. Micron 38: 824-833. 
LANGERK (1861). On the anatomy and physiology of the skin. BrJ Plast Surg 31:3-8.

LEE J, LEONARD M, OLIVER T, ISHIHARAA, JACOBSON K (1994). Traction forces generated by locomoting keratocytes. J Cell Biol 127: 1957-1964.

LEE RTH, ASHARANI P V., CARNEY TJ (2014). Basal keratinocytes contribute to all strata of the adult zebrafish epidermis. PLoS One 9: e84858.

LEGOFF L, LECUIT T (2016). Mechanical forces and growth in animal tissues. Cold Spring Harb Perspect Biol 8: a019232.

LEGOFF L, ROUAULT H, LECUIT T (2013). A global pattern of mechanical stress polarizes cell divisions and cell shape in the growing Drosophila wing disc. Development 140: 4051-4059.

LEVENTAL I, GEORGES PC, JANMEY PA (2007). Soft biological materials and their impact on cell function. Soft Matter3:299-306. Retrieved from: https://pubs.rsc.org

LORBERM, MILOBSKYSA(1968). Stretching of the skin in vivo. Amethod of influencing cell division and migration in the rat epidermis. J Invest Dermatol51:395-402.

LYU YS, SHI P liang, CHEN XL, TANG YX, WANG YF, LIU RR, LUAN XR, FANG Y, MEI RH, DU ZF, KE HP, MATRO E, LI LE, LIN ZY, ZHAO J, GAO X, ZHANG XN (2016). A Small Indel Mutant Mouse Model of Epidermolytic Palmoplantar Keratoderma and Its Application to Mutant-specific shRNA Therapy. Mol Ther Nucleic Acids 5: e299.

PELHAM RJJ, WANG Y-L (1997). Cell locomotion and focal adhesions are regulated by substrate flexibility. Proc Natl Acad Sci USA 94: 13661-13665.

PINHEIRO D, BELLAÏCHE Y (2018). Mechanical Force-Driven Adherens Junction Remodeling and Epithelial Dynamics. Dev Cell 47: 3-19.

RAGHAVAN S, BAUER C, MUNDSCHAU G, LI Q, FUCHS E (2000). Conditional Ablation of $\beta 1$ Integrin in Skin. J Cell Biol 150: 1149-1160.

RAMAN R, DAMLE I, ROTE R, BANERJEE S, DINGARE C, SONAWANE M (2016). APKC regulates apical localization of $\mathrm{Lgl}$ to restrict elongation of microridges in developing zebrafish epidermis. Nat Commun 7: 11643.

RAY S, FOOTE HP, LECHLER T (2013). Beta-Catenin protects the epidermis from mechanical stresses. J Cell Biol 202: 45-52.

REIS A, HENNIES HC, LANGBEIN L, DIGWEED M, MISCHKE D, DRECHSLER M, SCHRÖCK E, ROYER-POKORA B, FRANKE WW, SPERLING K, KÜSTER $W$ (1994). Keratin 9 gene mutations in epidermolytic palmoplantar keratoderma (EPPK). Nat Genet 6: 174-179.

REISCHAUERS, LEVESQUE MP, NÜSSLEIN-VOLHARD C, SONAWANEM (2009). Lgl2 executes its function as a tumor suppressor by regulating ErbB signaling in the zebrafish epidermis. PLoS Genet 5: e1000720.

SCHLUCK T, NIENHAUS U, AEGERTER-WILMSEN T, AEGERTER CM (2013). Mechanical Control of Organ Size in the Development of the Drosophila Wing Disc. PLoS One 8: e76171.

SILVER FH, SIPERKO LM, SEEHRA GP (2003). Mechanobiology of force transduction in dermal tissue. Ski Res Technol 9: 3-23.

SLANCHEV K, CARNEY TJ, STEMMLER MP, KOSCHORZ B, AMSTERDAM A, SCHWARZ H, HAMMERSCHMIDTM (2009). The epithelial cell adhesion molecule EpCAM is required for epithelial morphogenesis and integrity during zebrafish epiboly and skin development. PLoS Genet 5: e1000563.

SONAL, SIDHAYE J, PHATAK M, BANERJEE S, MULAY A, DESHPANDE O, BHIDE S, JACOB T, GEHRING I, NUESSLEIN-VOLHARD C, SONAWANE M (2014). Myosin Vb Mediated Plasma Membrane Homeostasis Regulates Peridermal Cell Size and Maintains Tissue Homeostasis in the Zebrafish Epidermis. PLoS
Genet 10: e1004614.

SONAWANE M, CARPIO Y, GEISLER R, SCHWARZ H, MAISCHEIN H-M NUESSLEIN-VOLHARD C (2005). Zebrafish penner/lethal giant larvae 2 functions in hemidesmosome formation, maintenance of cellular morphology and growth regulation in the developing basal epidermis. Development 132: 3255-3265.

SONAWANE M, MARTIN-MAISCHEIN H, SCHWARZ H, NUSSLEIN-VOLHARD C (2009). Lgl2 and E-cadherin act antagonistically to regulate hemidesmosome formation during epidermal development in zebrafish. Development 136: 1231-1240.

SQUIER CA (1980). The stretching of mouse skin in vivo: Effect on epidermal proliferation and thickness. $J$ Invest Dermatol 74: 68-71.

SUGIMURA K, LENNE P-F, GRANER F (2016). Measuring forces and stresses in situ in living tissues. Development 143: 186-196.

TINKLE CL, LECHLER T, PASOLLI HA, FUCHS E (2004). Conditional targeting of E-cadherin in skin: Insights into hyperproliferative and degenerative responses. Proc Natl Acad Sci USA 101: 552-557.

TINKLE CL, PASOLLI HA, STOKES N, FUCHS E (2008). New insights into cadherin function in epidermal sheet formation and maintenance of tissue integrity. Proc Natl Acad Sci USA 105: 15405-15410.

TOKUYAMA E, NAGAI Y, TAKAHASHI K, KIMATA Y, NARUSE K (2015). Mechanical stretch on human skin equivalents increases the epidermal thickness and develops the basement membrane. PLoS One 10: e0141989.

TRÄBER N, UHLMANN K, GIRARDO S, KESAVAN G, WAGNER K, FRIEDRICHS J, GOSWAMI R (2018). Polyacrylamide Bead Sensors for in vivo Quantification of Cell-Scale Stress in Zebrafish Development. bioRxiv: 420844.

TRUSCHEL ST, WANG E, RUIZ WG, LEUNG S-M, ROJAS R, LAVELLE J, ZEIDEL M, STOFFER D, APODACA G (2002). Stretch-regulated Exocytosis/Endocytosis in Bladder Umbrella Cells. Mol Biol Cell 13: 830-846.

TUNGGAL JA, HELFRICH I, SCHMITZ A, SCHWARZ H, GU"NZEL D, FROMM M, KEMLER R, KRIEG T, NIESSEN CM (2005). E-cadherin is essential for in vivo epidermal barrier function by regulating tight junctions. EMBO J 24: 1146-1156.

VARKI R, SADOWSKI S, UITTO J, PFENDNER E (2007). Epidermolysis bullosa. II. Type VII collagen mutations and phenotype-genotype correlations in the dystrophic subtypes. J Med Genet 44: 181-192.

WELLS AR, ZOU RS, TULU US, SOKOLOW AC, CRAWFORD JM, EDWARDS GS, KIEHART DP (2014). Complete canthi removal reveals that forces from the amnioserosa alone are sufficient to drive dorsal closure in Drosophila. Mol Biol Cell 25: 3552-3568.

WYATT TPJ, HARRIS AR, LAM M, CHENG Q, BELLIS J, DIMITRACOPOULOS A, KABLAAJ, CHARRAS GT, BAUM B (2015). Emergence of homeostatic epithelial packing and stress dissipation through divisions oriented along the long cell axis. Proc Natl Acad Sci USA 112: 5726-5731.

XU GK, LIU Y, ZHENG Z (2016). Oriented cell division affects the global stress and cell packing geometry of a monolayer under stretch. J Biomech 49: 401-407.

YOUNG P, BOUSSADIA O, HALFTER H, GROSE R, BERGER P, LEONE DP, ROBENEK H, CHARNAY P, KEMLER R, SUTER U (2003). E-cadherin controls adherens junctions in the epidermis and the renewal of hair follicles. EMBO $J$ 22: 5723-5733.

ZÖLLNER AM, HOLLAND MA, HONDA KS, GOSAIN AK, KUHL E (2013). Growth on demand: Reviewing the mechanobiology of stretched skin. J Mech Behav Biomed Mater 28: 495-509. 


\section{Further Related Reading, published previously in the Int. J. Dev. Biol.}

Xenopus cadherin $\mathbf{5}$ is specifically expressed in endothelial cells of the developing vascular system Herbert Neuhaus, Sanjeeva Metikala and Thomas Hollemann

Int. J. Dev. Biol. (2014) 58: 51-56

https://doi.org/10.1387/ijdb.140013hn

Microtubule disassembly prevents palatal fusion and alters regulation of the E-cadherin/catenin complex

Yukiko Kitase and Charles F. Shuler

Int. J. Dev. Biol. (2013) 57: 55-60

https://doi.org/10.1387/ijdb.120117yk

P-cadherin role in normal breast development and cancer

André Albergaria, Ana-Sofia Ribeiro, André-Filipe Vieira, Bárbara Sousa, Ana-Rita Nobre, Raquel Seruca, Fernando Schmitt and Joana Paredes Int. J. Dev. Biol. (2011) 55: 811-822

https://doi.org/10.1387/ijdb.113382aa

Expression of protocadherin-19 in the nervous system of the embryonic zebrafish

Qin Liu, Yun Chen, Fumitaka Kubota, Jean J. Pan and Tohru Murakami

Int. J. Dev. Biol. (2010) 54: 905-911

https://doi.org/10.1387/ijdb.092882ql

Expression of protocadherin 18 in the CNS and pharyngeal arches of zebrafish embryos Fumitaka Kubota, Tohru Murakami, Yuki Tajika and Hiroshi Yorifuji

Int. J. Dev. Biol. (2008) 52: 397-405

https://doi.org/10.1387/ijdb.072424fk

The expression of Fat-1 cadherin during chick limb development

Terence G. Smith, Nick Van Hateren, Cheryll Tickle and Stuart A. Wilson

Int. J. Dev. Biol. (2007) 51: 173-176

https://doi.org/10.1387/ijdb.062221tg

Cadherin- 6 is required for zebrafish nephrogenesis during early development

Fumitaka Kubota, Tohru Murakami, Kenji Mogi and Hiroshi Yorifuji

Int. J. Dev. Biol. (2007) 51: 123-129

https://doi.org/10.1387/ijdb.062200fk

Molecular aspects of cancer metastasis: extracellular regulation of the E-cadherin/ catenin complex

M Mareel, T Boterberg, V Noë, E Bruyneel and M Bracke

Int. J. Dev. Biol. (1996) 40: S65-S66

http://www.intjdevbiol.com/web/paper/9087699
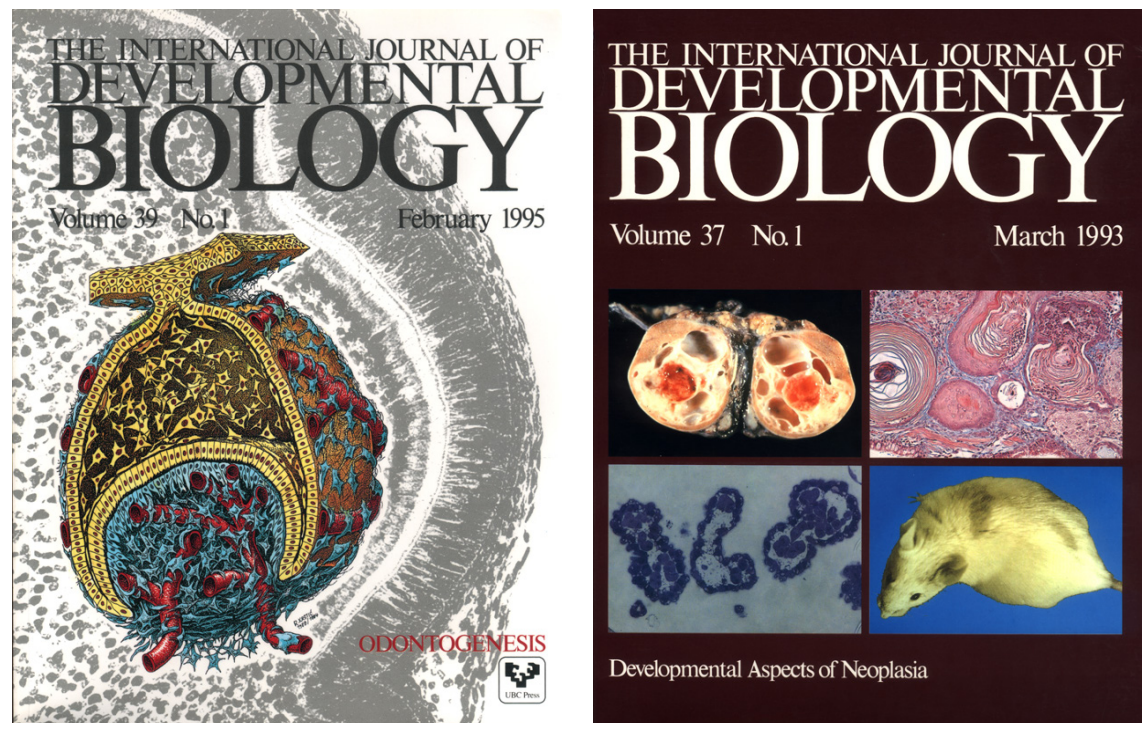

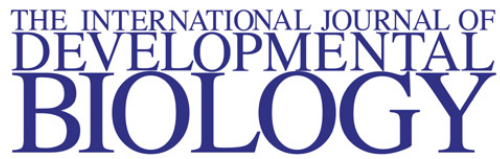

Volume 48 Nos. $5 / 6$

Special issue

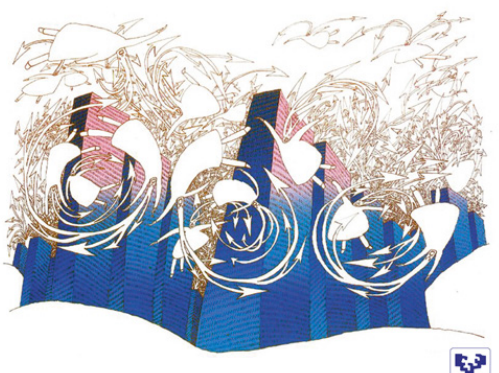

Inyasion in cancer and embryonic development

$\sum_{4}$
unchom

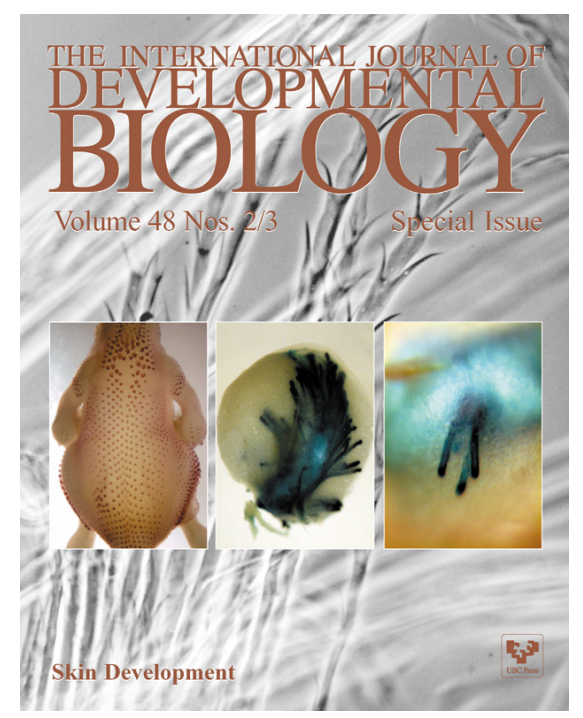

